\title{
Process characterization and analysis of ceramic powder bed fusion
}

\author{
Kevin Florio ${ }^{1}$. Dario Puccio ${ }^{2} \cdot$ Giorgio Viganò $^{2} \cdot$ Stefan Pfeiffer $^{3,4}$ - Fabrizio Verga ${ }^{5}$. Marco Grasso ${ }^{2}$. \\ Bianca Maria Colosimo ${ }^{2} \cdot$ Thomas Graule $^{3,4} \cdot$ Konrad Wegener $^{1}$
}

Received: 2 December 2020 / Accepted: 1 July 2021 / Published online: 27 July 2021

(C) The Author(s) 2021

\begin{abstract}
Powder bed fusion (PBF) of ceramics is often limited because of the low absorptance of ceramic powders and lack of process understanding. These challenges have been addressed through a co-development of customized ceramic powders and laser process capabilities. The starting powder is made of a mix of pure alumina powder and alumina granules, to which a metal oxide dopant is added to increase absorptance. The performance of different granules and process parameters depends on a large number of influencing factors. In this study, two methods for characterizing and analyzing the PBF process are presented and used to assess which dopant is the most suitable for the process. The first method allows one to analyze the absorptance of the laser during the melting of a single track using an integrating sphere. The second one relies on in-situ video imaging using a highspeed camera and an external laser illumination. The absorption behavior of the laser power during the melting of both single tracks and full layers is proven to be a non-linear and extremely dynamic process. While for a single track, the manganese oxide doped powder delivers higher and more stable absorptance. When a full layer is analyzed, iron oxide-doped powder is leading to higher absorptance and a larger melt pool. Both dopants allow the generation of a stable melt-pool, which would be impossible with granules made of pure alumina. In addition, the present study sheds light on several phenomena related to powder and meltpool dynamics, such as the change of melt-pool shape and dimension over time and powder denudation effects.
\end{abstract}

Keywords Additive manufacturing · Selective laser melting · Powder bed fusion · Ceramics · Alumina · Absorptance measurements $\cdot$ Integrating sphere $\cdot$ High-speed vision

\section{Introduction}

There is a growing interest for additive manufacturing in several industries, because of the possibility to build complex and personalized three-dimensional shapes with relatively short

Kevin Florio

florio@iwf.mavt.ethz.ch

1 Institute of Machine Tools and Manufacturing, ETH Zurich, Leonhardstrasse 21, 8092 Zurich, Switzerland

2 Department of Mechanical Engineering, Politecnico di Milano, Campus Bovisa Sud-via La Masa 1, 20156 Milan, Italy

3 Laboratory for High Performance Ceramics, Empa - Swiss Federal Laboratories for Materials Science and Technology, Überlandstrasse 129, 8600 Dübendorf, Switzerland

4 Institute of Ceramic, Glass and Construction Materials, TU Bergakademie Freiberg, Agricolastraße 17, 09599 Freiberg, Germany

5 Inspire, Innovation Center for Additive Manufacturing Switzerland (icams), Lerchenfeldstrasse 3, 9014 St Gallen, Switzerland lead-time from design to the final product, and low waste of raw materials. The advantages are especially relevant for small series or unique parts, but the choice of possible materials is so far limited, as it was summarized in Sing et al. [1]. Regarding ceramics, only indirect additive manufacturing is currently possible with commercial machines, as shown in Travitzky et al; Zocca et al. [2, 3]: green parts can be produced by such devices and they need further sintering in a furnace. Many researchers [4-11] attempted direct additive manufacturing of engineering oxide ceramics, such as alumina and zirconia in the past years, but several problems arose, such as thermal stress-induced cracks and poor absorptance of ceramic materials at visible and near infrared laser wavelengths. Cracks were thoroughly analyzed after the laser melting of single tracks in Fan et al. [10] and Zheng et al. [12]. The only possibility to achieve crack-free parts for engineering ceramics was by using two lasers, one for pre-heating and one for selective melting, as it was done in Wilkes et al. [5] and Wilkes et al. [7]. However, the part size and roughness were strongly limited. The poor laser light absorptance was solved with the use of carbon additives or silicon carbide in 
Juste et al, Verga et al; Moniz et al. [4, 6, 9], while the use of other oxide ceramics as absorptance-enhancer within granules was first presented in Florio et al; Pfeiffer et al.; Makowska et al. [13-15].

The choice of additives was never justified by specific material properties, and their effect on laser-matter interaction and on the thermodynamics of the melt pool was never investigated thoroughly. Even though different additives and different processes are presented, process understanding and process characterization are still superficial.

Temperature during laser melting of alumina was measured by Qian et al. [16]. In-line pyrometry and spectrometry enabled high temporal resolution measurements and proved to be useful for in-situ process monitoring. However, their physical meaning is not always easy to interpret, since measurements are spatially integrated, and they refer to the average values of temperature profiles around and within the melt pool.

On the contrary, in-situ high-speed video imaging in Qian et al. [16] using external laser illumination proved to be useful for gaining a deeper process understanding and setting appropriate laser parameters, but a numerical correlation between laser parameters and the melt-pool evolution was missing. Insitu high-speed video imaging with external laser illumination was also used in Wilkes et al. [17] and Hagedorn [18], in order to investigate phenomena that affect the poor surface roughness of parts built by L-PBF with high-temperature preheating using pure alumina-zirconia powder. In Hagedorn [18], an integrating sphere was used to measure the laser light absorptance during the process. However, no material development was presented and therefore the laser absorptance for near infrared laser was extremely unstable. Finally, in Moniz et al. [9] and Moniz et al. [19], the absorptance of alumina powder with additions of carbon and silicon carbide was analytically calculated, based on the melt-pool dimensions. This method was practical, but it neglected the complex thermodynamical phenomena that occur during laser powder bed fusion (L-PBF). In-situ high-speed video imaging in Moniz et al. [9] showed that powder denudation for ceramics is more relevant than for metals, but the lack of external illumination limited the contrast of the pictures for more detailed and quantitative analysis.

In the present work, two L-PBF process characterization techniques are proposed as methods to increase the process understanding and improve the selection process of a suitable powder dopant. The first method is the in-situ absorptance measurement of laser light. The second method consists of in-situ high-speed video imaging with external illumination to validate the results of the absorptance measurements and observe the melt-pool size evolution in time and the powder denudation mechanism. These process characterization techniques have been designed und used to compare two different dopants for L-PBF of alumina, namely iron oxide and manganese oxide. They were first proposed and analyzed in Pfeiffer et al. [20], where an optimization in terms of packing density was performed on alumina granules containing the two dopants. The granules absorption at room temperature was analyzed through Kubelka-Munk model, showing that the iron oxide-doped alumina granules have a significantly lower absorption for the infrared (IR) wavelength (1070 $\mathrm{nm})$, compared to manganese oxide.

The two doped powders are compared in the current publication using an IR and the mentioned characterization techniques, which are presented in Section 2. The results and the discussion is presented in the following Section 3: the higher absorption of the manganese oxide-doped powder observed in Pfeiffer et al. [20], indeed, led to larger and more stable melt pool in single tracks experiments. However, when full layers were analyzed, the result reversed, probably due to the change in crystalline phase experienced by the powder after melting and re-solidification.

\section{Experimental setup}

\subsection{Laser and optics}

The experiments were conducted in an open laser laboratory. The adopted laser was a Nd:YAG $200 \mathrm{~W}$ continuous wave infrared laser (redPOWER, SPI Lasers Ltd, UK). The wavelength was $1070 \mathrm{~nm}$, and the beam was focused by a telecentric f-theta lens (S4LFT3162/328, Sill optics, Germany). The scanning was performed by a scan head with galvanometer-actuated mirrors (SS-12 [Y] D2, Raylase, Germany).

\subsection{Materials}

The starting material was produced through spray granulation. Alumina granules with two different nanometric powder dopants were compared: iron oxide (Fe2O3, L2715D, BASF SE, Ludwigshafen, Germany) and manganese oxide (MnO2, US3319, US Research Nanomaterials, Houston, USA). Both dopants have a spherical shape. The iron oxide powder has a $\mathrm{d}_{50}$ of $53 \mathrm{~nm}$ after dispersion in water with $3.0 \mathrm{wt} \%$ of citrate as dispersant, $20 \mathrm{~min}$ of vibration milling and subsequent $24 \mathrm{~h}$ of roll milling. The size distribution was measured by dynamic light scattering (DLS) as described in Pfeiffer et al. [14]. The manganese oxide powder used as dopant has a $d_{50}$ of $172 \mathrm{~nm}$ after similar dispersion in water. More details about the dispersion procedure can be found in Pfeiffer et al [14] and Pfeiffer et al. [20]. Two alumina powders were used for the spray drying of granules: one is micron-sized (AA3, $\mathrm{d}_{50}$ of 3.7 $\mu \mathrm{m}$, Sumitomo, Chemical Co. LTD, Tokyo, Japan), the other nanometric (Taimicron TM-DAR, $\mathrm{d}_{50}$ of $18 \mathrm{~nm}$, Taimei Chemicals Co. LTD, Tokyo, Japan). The granules were finally 
dry mixed with pure alumina powder (AA18, $\mathrm{d}_{50}$ of $18.6 \mu \mathrm{m}$, Sumitomo, Chemical Co. LTD, Tokyo, Japan) in a volumebased ratio of 70 to 30 . This mix was performed to find the right compromise between flowability, packing density, and light absorptance. In fact, the particle size and shape clearly have a great influence on laser absorptance. As shown in Pfeiffer et al. [14], the addition of pure alumina powder improves the packing density. The higher density is due to the larger density of the AA18 powder, compared to the granules, which can be partially hollow. The amount of 30 vol\% AA18 significantly improves powder packing density, without decreasing the laser absorptance. The material properties and the spray granulation process are explained in more details in Table 1 and in Pfeiffer et al. [14].

Densities were measured with helium pycnometry (AccuPyc II 1340, Micrometrics, Norcross/GA, USA). The relative apparent and tapped densities were calculated with respect to the helium pycnometry-measured densities. The median particle size of the granules $\left(\mathrm{d}_{50}\right)$ was measured by laser scattering (LS 13320, Beckman Coulter GmbH, Krefeld, Germany).

\subsection{Absorptance measurement setup}

The two different process characterization techniques require two separate experimental setups, because in-situ high-speed video imaging could not be carried out within the $150-\mathrm{mm}$ integrating sphere. Figure 1 shows the experimental setup for the measurement of the absorptance. The reflectance (R) was measured using an integrating sphere, and the transmission was assumed to be zero, since the extinction coefficient of molten alumina is relatively high $[21,22]$. The absorptance (A) is therefore calculated as follows:

$A=1-R$

The integrating sphere was coated internally with barium sulfate, and it was equipped with $30-\mathrm{mm}$ ports (GigahertzOptik UPB-150-ARTA, Germany). The upper port was open for the incoming laser, whereas the sample was placed at the bottom port, and a detector was placed at the third port, which was covered by a coated baffle. A clear limit of the

Table 1 Granules properties

\begin{tabular}{lccccc}
\hline Powder & $\begin{array}{c}\text { Dopant } \\
\text { amount }\end{array}$ & $\begin{array}{l}\text { Particle } \\
\text { size } \\
\left(\mathrm{d}_{50}\right)\end{array}$ & $\begin{array}{l}\text { Measured } \\
\text { density }\end{array}$ & $\begin{array}{l}\text { Apparent } \\
\text { density }\end{array}$ & $\begin{array}{c}\text { Tapped } \\
\text { density }\end{array}$ \\
\hline $\begin{array}{c}\mathrm{Fe}_{2} \mathrm{O}_{3} \text {-doped } \\
\text { alumina }\end{array}$ & $\begin{array}{c}0.68 \\
\mathrm{wt} \%\end{array}$ & $\begin{array}{c}32.08 \\
\mu \mathrm{m}\end{array}$ & $\begin{array}{c}3.89 \\
\mathrm{~g} / \mathrm{cm}^{3}\end{array}$ & $42.9 \%$ & $50.9 \%$ \\
$\begin{array}{c}\mathrm{MnO}_{2} \text {-doped } \\
\text { alumina }\end{array}$ & $\begin{array}{c}0.86 \\
\mathrm{wt} \%\end{array}$ & $\begin{array}{c}30.48 \\
\mu \mathrm{m}\end{array}$ & $\begin{array}{c}3.86 \\
\mathrm{~g} / \mathrm{cm}^{3}\end{array}$ & $44.2 \%$ & $51.9 \%$ \\
\hline
\end{tabular}

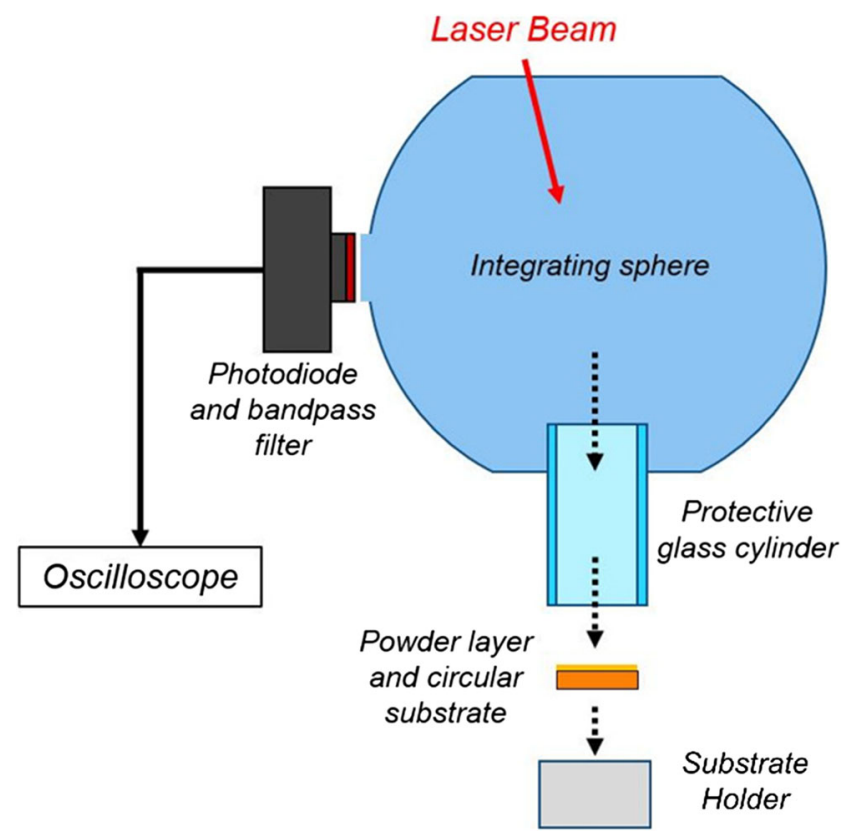

Fig. 1 Schematic of absorptance measurement setup

absorptance setup is that no air or gas flow can be ensured within the integrating sphere, which may influence the results, especially in the case of ejection of large spatters. A picture of the absorptance measurement setup is shown in Fig. 2.

A cylinder made of quartz glass was placed above the sample, to protect the sphere from the spatters ejected by the lasermaterial interaction. The influence of the cylinder on the detector measurements was proven to be negligible, comparing the value of the reference with and without the cylinder.

The detector was an amplified silicon detector (PDA100A, Thorlabs, USA), and it was connected to an oscilloscope, capable of acquiring a signal with a frequency of $10 \mathrm{kHz}$. In front of the photodiode, neutral density filters were placed in order to avoid photodiode light saturation. In addition, a 1070nm laser line filter (FB1070-10, Thorlabs, USA) was added, such that only the reflected laser light was taken into account, filtering out the light coming from the melt-pool emission.

The current voltage measured by the oscilloscope during the sample scanning $(U)$ was then compared with the reflectivity of a standard sample $\left(\mathrm{U}_{\text {ref }}\right)$ calibrated by GigahertzOptik GmbH (Germany) according to the ISO17025 standard:

$\boldsymbol{R}=\frac{U}{U_{r e f}}$

The laser power was set to $30 \mathrm{~W}$; the spot size to $170 \mu \mathrm{m}$ and 5 different scanning speeds between 12 and $100 \mathrm{~mm} / \mathrm{s}$ were tested. Single tracks of $10-\mathrm{mm}$ length were scanned. Each set of scanning parameters was repeated five times.

A powder layer of $100 \mu \mathrm{m}$ was deposited with a blade on circular substrates of $27 \mathrm{~mm}$ in diameter made of granules pressed with $114 \mathrm{MPa}$ and heat treated for $1 \mathrm{~h}$ at $1000{ }^{\circ} \mathrm{C}$ to 


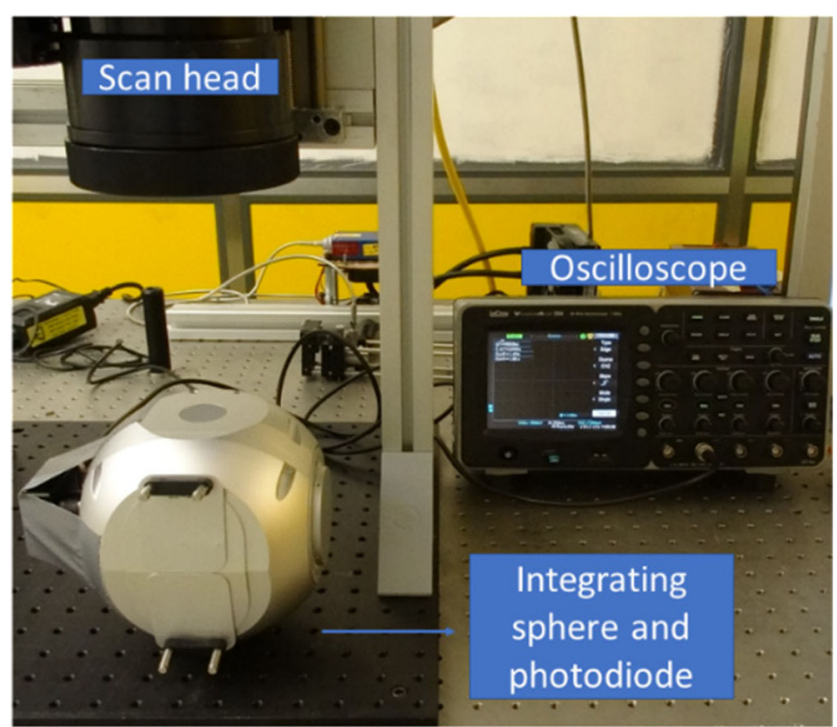

Fig. 2 Picture of the absorptance experiment setup, including the oscilloscope, the integrating sphere with the attached photodiode and the scan head through wich the laser is deviated

form a pre-consolidated substrate. The color of the substrates was only slightly faded compared to the powder: gray for manganese oxide-doped alumina and redorange for iron oxide-doped alumina. As shown in Fig. 3, after laser processing, the color of the newly solidified material changes because some metastable phases are generated during the rapid cooling, as already analyzed in Makowska et al. [15].

In addition to single track analysis, the absorptance during the L-PBF of a full layer $(4 \times 4 \mathrm{~mm})$ was measured. In this case, the experimental setup presented in Florio et al. [13] was used. The oscilloscope was set to a sampling rate of $2500 \mathrm{~Hz}$, which allowed the acquisition of data for around $4 \mathrm{~s}$.

The experiments for full layer production included three levels of power $(10 \mathrm{~W}, 18.5 \mathrm{~W}$, and $30 \mathrm{~W})$ and three levels of energy densities $\left(300,200\right.$, and $\left.100 \mathrm{~J} / \mathrm{mm}^{3}\right)$. Since at 10 and $18.5 \mathrm{~W}$, the layers were more homogeneous, the absorptance measurements focused then on these two levels of power. The corresponding scan speeds were $25.6 \mathrm{~mm} / \mathrm{s}, 12.8 \mathrm{~mm} / \mathrm{s}$, and $8.6 \mathrm{~mm} / \mathrm{s}$ for the power level of $10 \mathrm{~W}$; and $47.4 \mathrm{~mm} / \mathrm{s}, 23.7$ $\mathrm{mm} / \mathrm{s}$, and $15.8 \mathrm{~mm} / \mathrm{s}$ for the power level of $18.5 \mathrm{~W}$. The spot size was set to $130 \mu \mathrm{m}$.
The first three layers were measured, and the experiments were replicated three times. Table 2 summarizes the experimental settings.

\subsection{High-speed camera setup with external laser illumination}

Both the high-speed camera and the illuminating laser were placed off-axially with respect to the processing laser. The aim of the experiment was to observe the melt-pool evolution and the process-induced interactions between powder bed, meltpool, and process by-products.

The same laser and scanning parameters as mentioned in sub-section 2.3 were analyzed. Each single-track experiment was repeated five times.

For both, single-tracks and full layers, the substrates and powder layers were prepared similarly to the one described in sub-section 2.3, with the addition of a suction unit for ensuring a constant airflow above the melt-pool, which is useful to remove the spatters from the scanned area and to create conditions more similar to the real process. The full layers were recorded for one layer after building 20 layers, so that a midprocess condition was achieved.

A defocused $10 \mathrm{~W} 445-\mathrm{nm}$ blue diode laser (Necsel blue laser $44510 \mathrm{~W}$, USHIO Inc., USA) was used to illuminate the sample during the camera acquisition time.

The high-speed camera (Phantom v12.1, AMETEK, USA) was equipped with a 100-mm macro lens (Makro-Planar 2/ 100 ZF T* 15589006, Carl Zeiss, Germany). The resolution was $800 \times 600$ pixels, the frame rate was $5000 \mathrm{fps}$, and the exposure time was $190 \mu \mathrm{s}$.

A blue laser-line filter (FB450-10, Thorlabs, USA) was added such that only the blue laser light reflected by the sample was acquired. This allowed filtering out the 1070-nm laser light and the bright emissions from the melt-pool. Without the external laser illumination, the picture would be either overexposed or underexposed, because the light emitted by the melt-pool is considerably more intense than the light emitted by a standard diffuse light illumination commonly used for high-speed vision. The complete setup is shown in Figure 4.

A perspective correction operation was applied to raw videos. Each greyscale frame was then converted into a binary
Fig. 3 Left picture: iron oxidedoped alumina powder. Right picture: manganese oxide-doped alumina powder
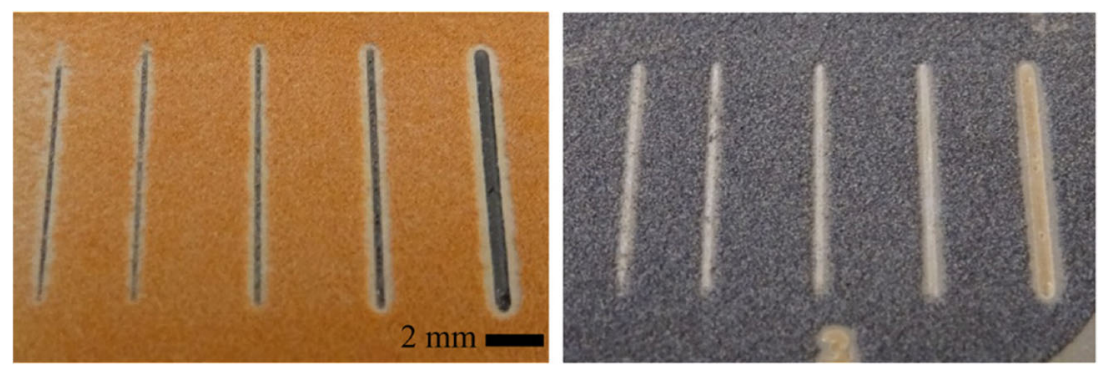
Table 2 Parameters and levels of the powder absorptance experiments for full layers

\begin{tabular}{lll}
\hline Parameter & N. of levels & Levels \\
\hline Doping & 2 & $\mathrm{MnO}_{2} ; \mathrm{Fe}_{2} \mathrm{O}_{3}$ \\
Laser power $[\mathrm{W}]$ & 2 & $10 ; 18.5$ \\
Energy density $\left[\mathrm{J} / \mathrm{mm}^{3}\right]$ & 3 & $100 ; 200 ; 300$ \\
\hline
\end{tabular}

image through a thresholding procedure. The threshold was chosen to be the same for each frame. The binarization operations enabled the identification of two different categories of bright connected components, i.e., the spatter particles and the melt pool. The latter was easily distinguishable because of its larger size. In the following analysis, spatters were filtered out by focusing on the melt-pool alone.

In addition to the isolation and characterization of meltpool properties, the denudation zone was identified and studied for single tracks too, thanks to high-speed video processing. The denudation zone is a region of the powder bed where there is a lack of powder material. The measurements on the denudation zone were performed for each video acquisition after the end of the process, when the spatters were not visible anymore. The extremities of the track were excluded from the analysis, because in these areas the laser may not be at a constant speed yet. Therefore, only the steady state region of the track was considered as shown in Fig. 5. The ratio between the denudation zone width $\left(w_{D}\right)$ and the melt track width $\left(w_{M}\right)$ is calculated in pixels along the scanning direction. If the ratio

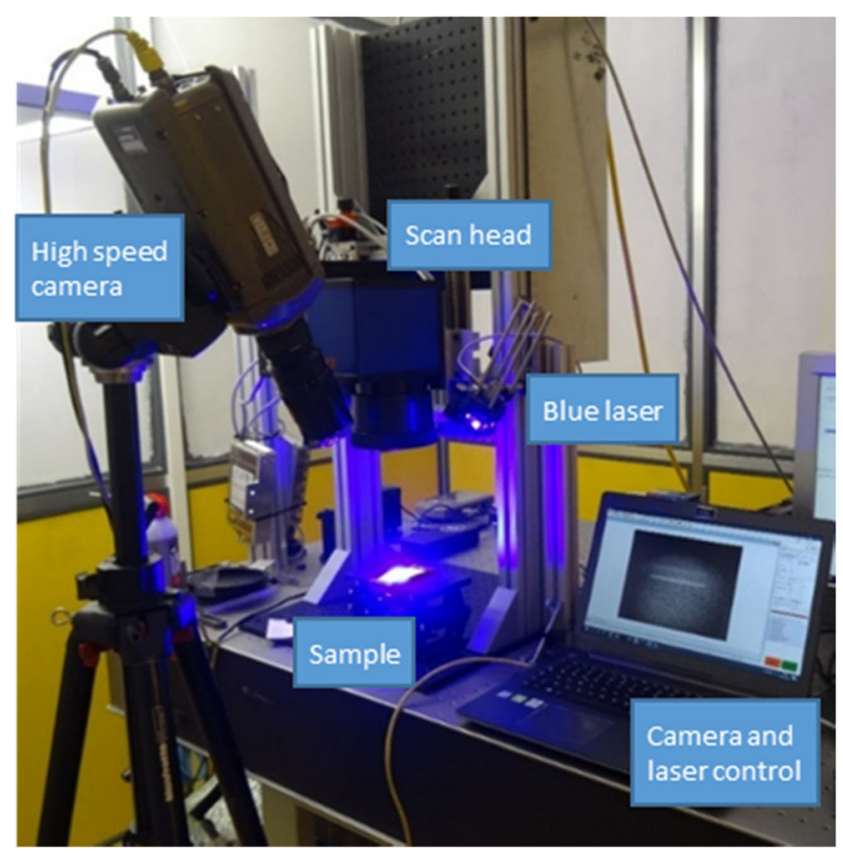

Fig. 4 Picture of the high-speed camera setup including the blue laser for illumination (which is activated in the picture) and relative controls. The scan head deviates the laser input for melting
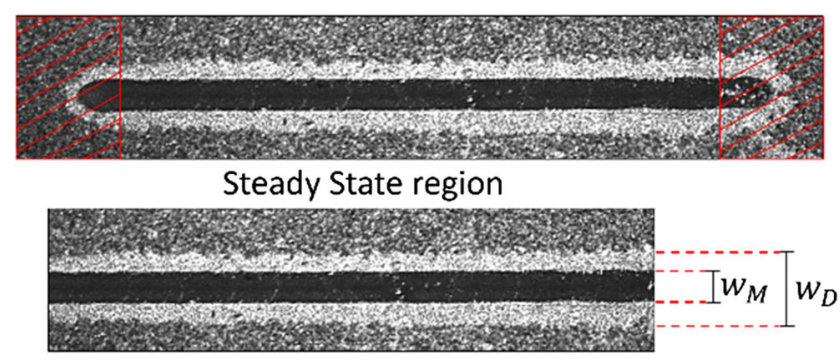

\section{Region not included in the analysis}

Fig. 5 .Definition of denudation zone width and melt-pool width. The region excluded from the denudation zone analysis is marked in red

$w_{D} / w_{M}$ is 1 , the denudation zone is equal to the track of solidified material and therefore powder bed is not disrupted beyond the melt track.

\section{Results and discussion}

\subsection{Absorptance measurements-single tracks}

Two examples of absorptance measurements are shown in Fig. 6. One refers to iron oxide-doped powder and the other to manganese oxide-doped powder. The measurements shown in Fig. 6 were performed with a laser scanning speed of $100 \mathrm{~mm} / \mathrm{s}$.

The absorptance of the two powders differs in both average and variance. Manganese oxide-doped powder has a higher average absorptance but with a lower variance. This is an indication that the melt-pool is more unstable for the ironoxide-doped powder, which could lead to manufacturing defects, such as balling or porosity.

The comparison of the absorptance and its variance for the two powder dopants at different scanning speeds is shown in Fig. 7. It can be noted that, for both powders, the absorptance decreases when the speed is increased from 12 to $40 \mathrm{~mm} / \mathrm{s}$. The absorptance is near to 1 at the low scanning speed of 12 $\mathrm{mm} / \mathrm{s}$, meaning that the majority of laser energy is absorbed by the melt-pool and only a small fraction is reflected.

For manganese oxide-doped powder above a scanning speed of $40 \mathrm{~mm} / \mathrm{s}$, the absorptance is practically constant, while a reduction of absorptance for iron oxide at higher speed is evident. This could be due to the fact that a larger portion of laser energy is absorbed by the melt-pool at low scanning speed, in agreement with the results presented in Heeling et al. [23]. Since alumina has a high absorptance when molten, the effect of the dopant is negligible at low speed when the laser is hitting mainly the melt-pool. At higher speed, on the contrary, the absorptance of the powder is more important, and manganese oxide-doped powder, which is black, keeps a higher absorptance compared to the iron oxide-doped powder. 

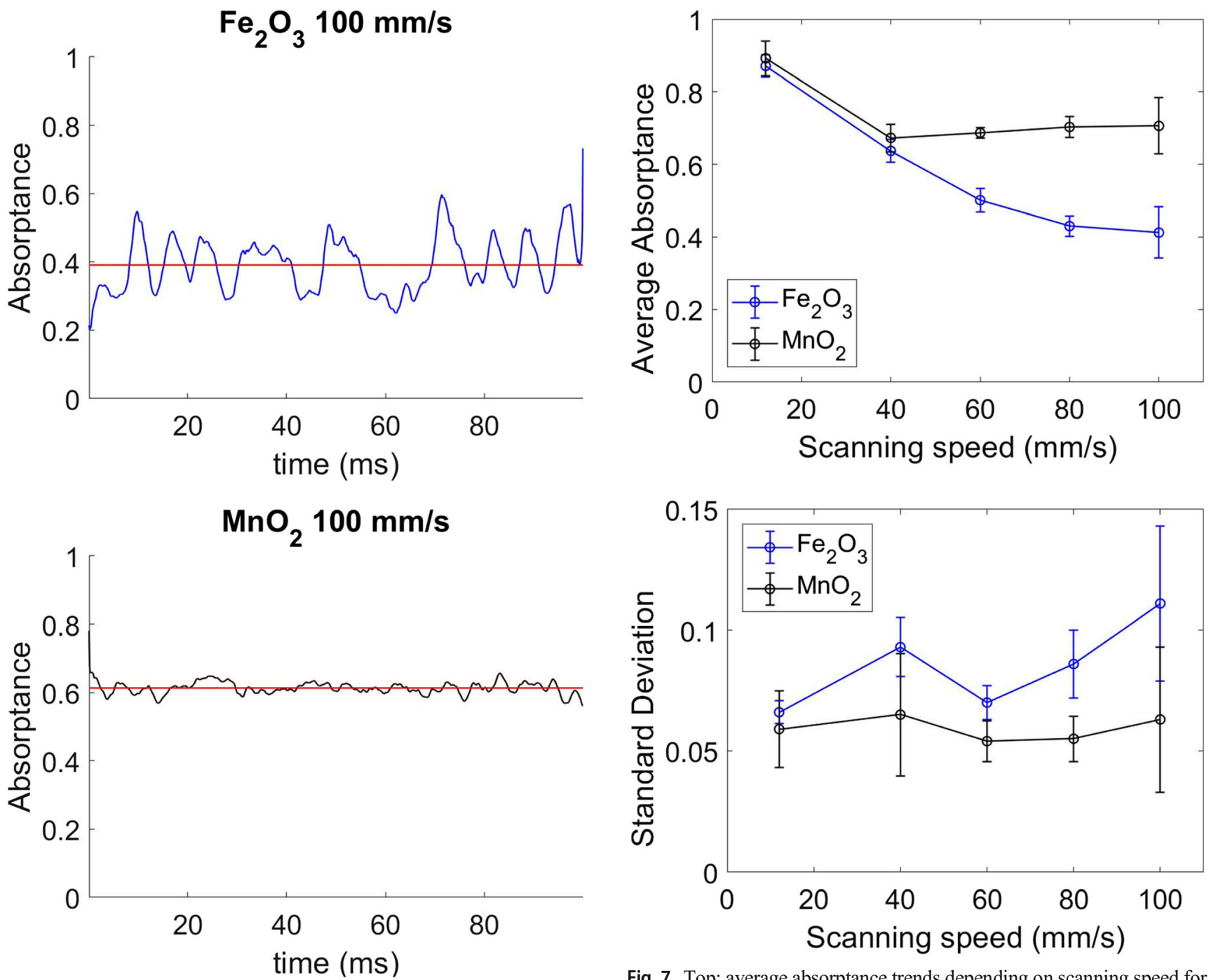

Fig. 6 Examples of absorptance measurements. Top: iron oxide-doped powder. Bottom: manganese oxide-doped powder. The red line average reflectance over time. The power was set to $30 \mathrm{~W}$

The influence of powder absorptivity could be more relevant for L-PBF of ceramics compared to metals because of the different material properties, such as higher heat conduction, viscosity, and melting temperature. In addition, in Heeling et al. [23], the effect of powder attracted into the melt-pool (see Sub-section 3.2) was neglected. These powder particles could absorb, reflect, or scatter the laser light, reducing or increasing the actual energy input into the melt-pool differently between the two powder dopants.

The analysis of the standard deviation in Fig. 7 confirms the already mentioned difference: the absorptance of the manganese oxide-doped powder has consistently lower standard deviation than the absorptance of the iron oxide-doped powder at every scanning speed. This can be an indication that the process is more stable when manganese oxide dopant is used.

Fig. 7 Top: average absorptance trends depending on scanning speed for two different powder dopants. Bottom: standard deviation of absorptance within each experiment. Power of $30 \mathrm{~W}$ was set

\subsection{High-speed video image analysis—single tracks}

Some examples of high-speed video frames for different scanning speeds are shown in Fig. 8. The different sizes of melt-pool at different scanning speeds are evident. The melt-pool appears bright, either because the infrared emission of light from the melt-pool is high enough to be visible despite the laser line filter or because the flat surface of the melt-pool is reflecting the blue laser illumination better than the powder.

Around the melt-pool, a powder-denudated zone is visible. In-situ video imaging shows that the denudation zone is generated by the powder particles that are attracted into the meltpool even though they are not on the scanning track. A similar phenomenon has been already shown for metals in previous studies [24]. This is due to convection flows around the meltpool, which attracts the powder particles near the laser track into the melt-pool. Denudation appears to be more 

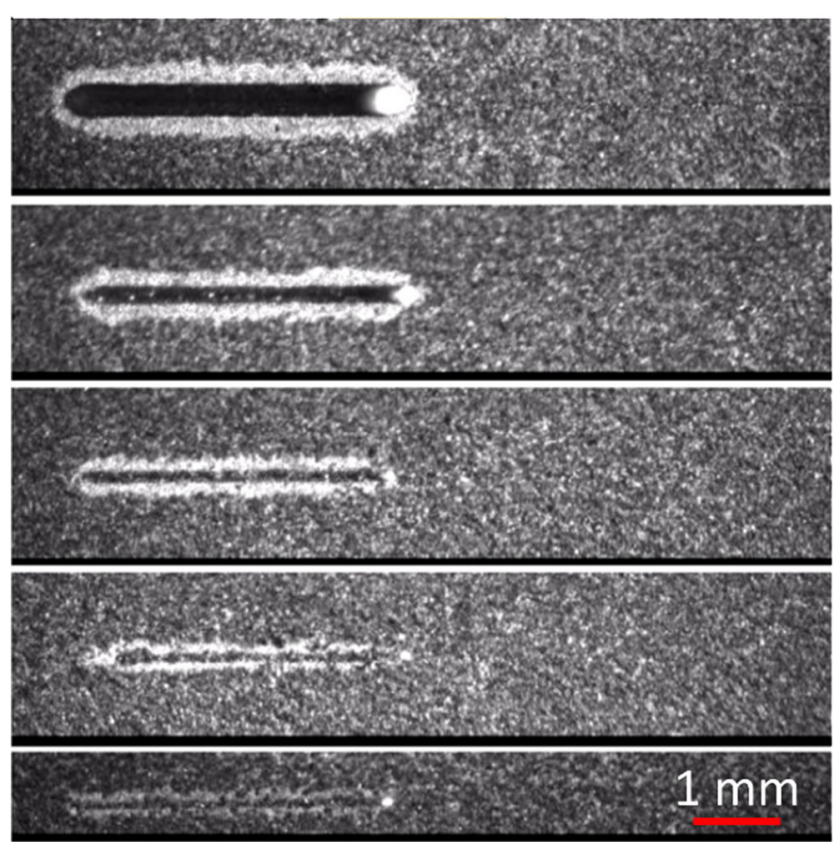

Fig. 8 Examples of high-speed camera recordings of single tracks with external laser illumination. From top to bottom, the scanning speeds are $12,40,60,80$, and $100 \mathrm{~mm} / \mathrm{s}$. Power was set to $30 \mathrm{~W}$

pronounced in ceramics, probably because of the higher melting temperatures and therefore higher processing temperatures.

Another interesting observation is that the melt-pool is not always stable when iron-oxide powder is used, as already predicted by absorptance measurements with the integrating sphere. This is clearly shown by Fig. 9, in which the melt-pool disappears at around $25 \mathrm{~ms}$. This event probably corresponds to a drop in absorptance.

Figure 10 shows the time series of melt pool areas during one scanned track for the two compared powders. Figure 10

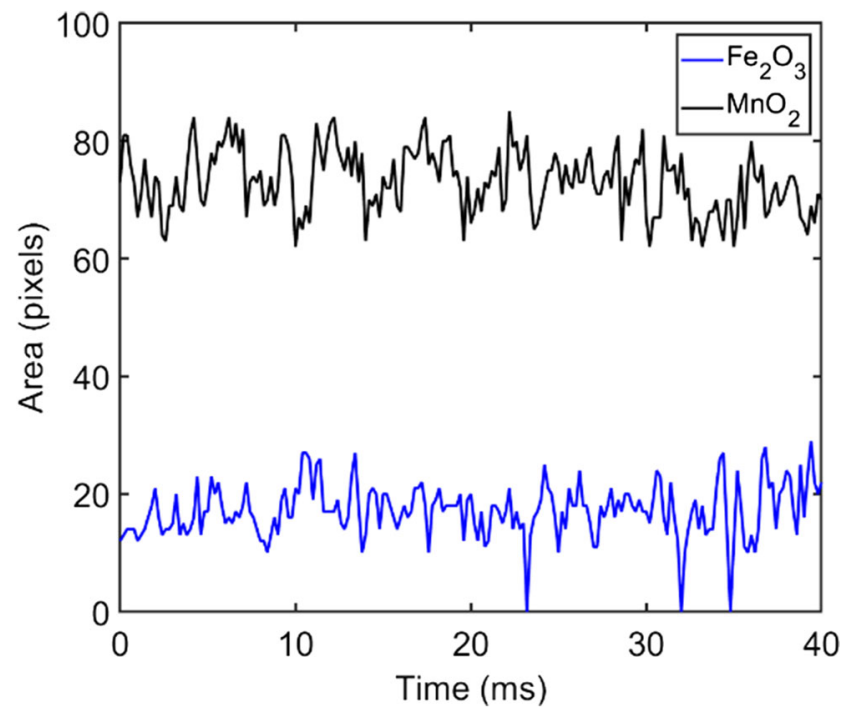

Fig. 10 Area of the melt pool during a scan track with the two different powders. The iron oxide-doped powder led to a smaller melt-pool, which completely disappeared in several occasions. Scan speed was $100 \mathrm{~mm} / \mathrm{s}$ and power $30 \mathrm{~W}$

shows that the disappearance of the melt-pool is not consistently happening at regular intervals, but it is more probably an effect of stochastic instabilities. Generally speaking, instabilities in L-PBF of ceramics may be due to (i) the poor powder absorptance, (ii) the high melting temperature, which leads to high thermal dissipation, and (iii) the insufficient flowability of the powder. Since flowability, melting temperature, and thermal properties of the two tested powders were very similar, the difference in the behavior captured in Figs. 9 and 10 could be explained mainly by the different laser absorptances of the two dopants.

The melt-pool area and denudation zone were measured for both powders at different speeds. Results are shown in Fig. 11.
Fig. 9 High-speed camera pictures at $5000 \mathrm{fps}$ for $100 \mathrm{~mm} / \mathrm{s}$ speed and $30-\mathrm{W}$ power with a picture filter to highlight the edges. The melt-pool is smaller and disappears at the frame corresponding to $25 \mathrm{~ms}$ for iron oxide doped powder
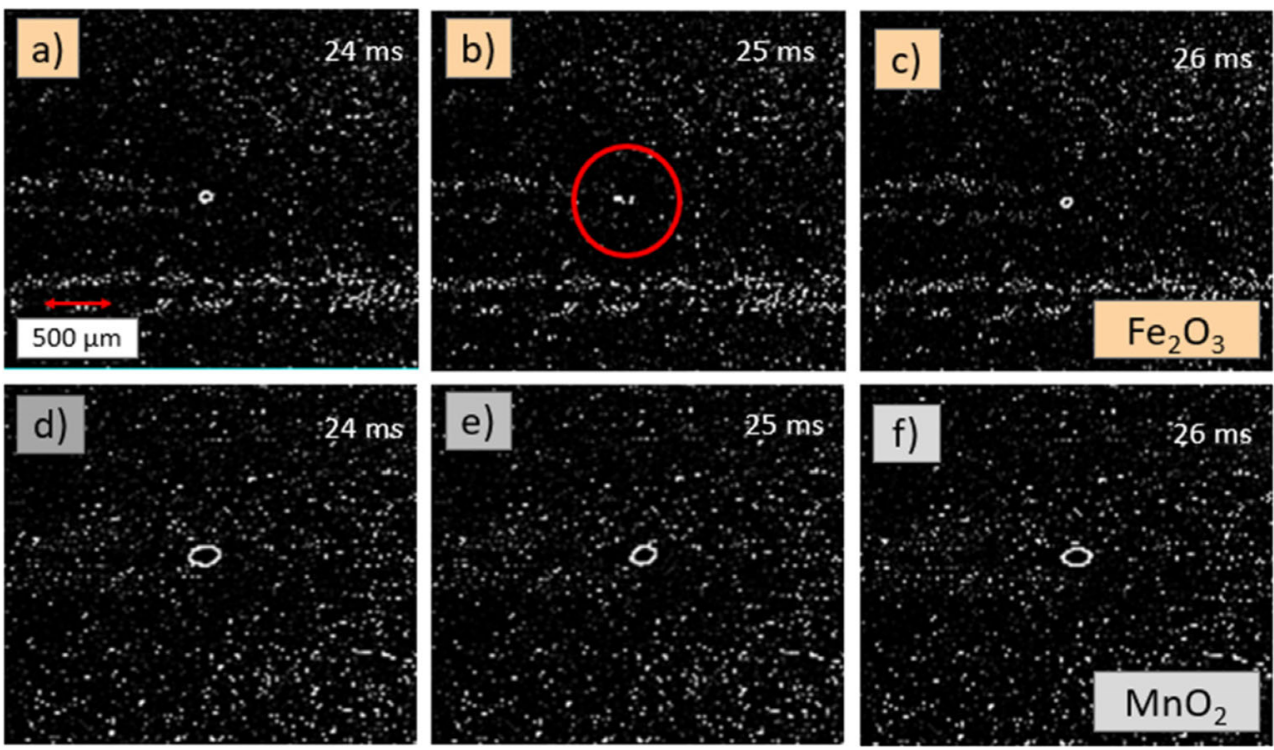

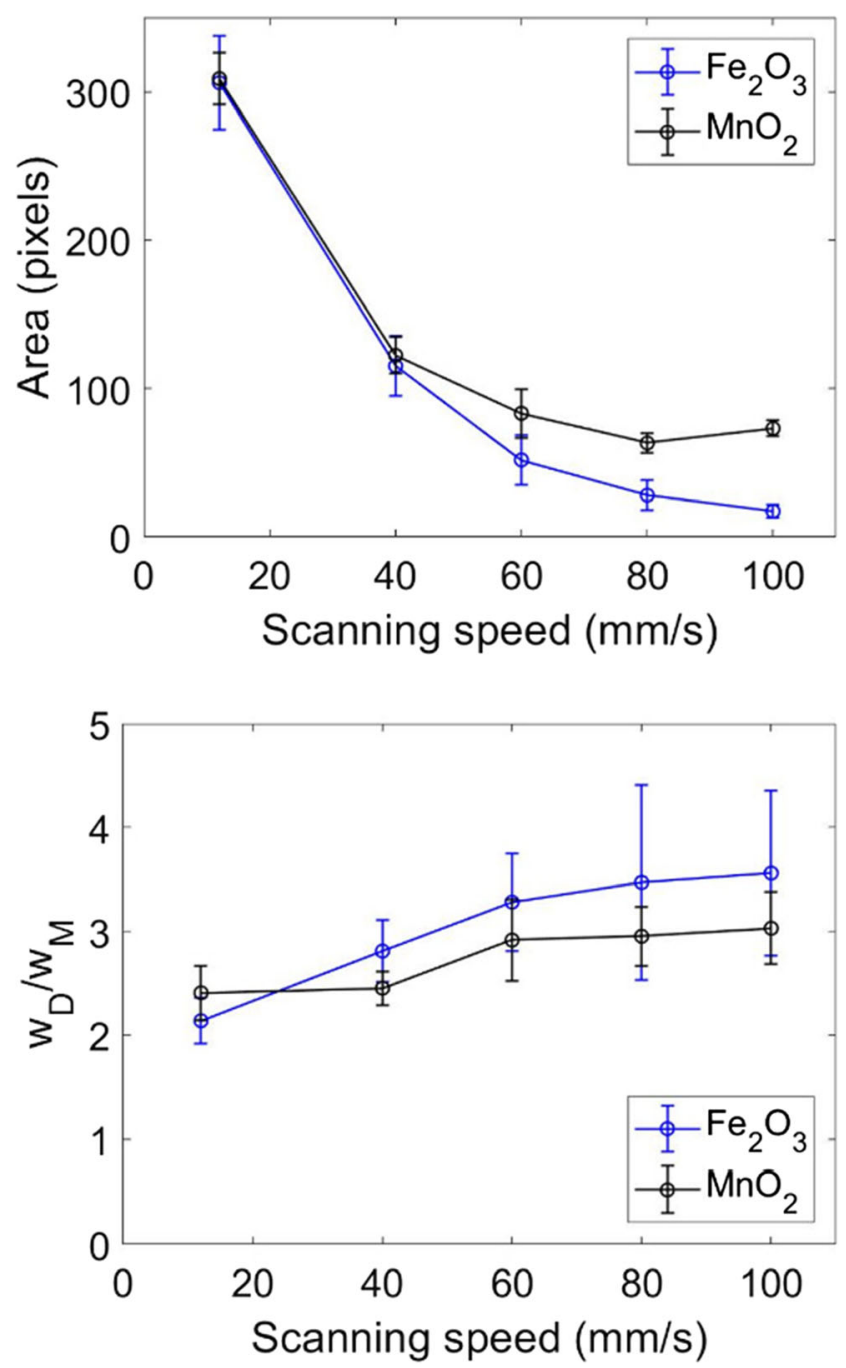

Fig. 11 Top: melt-pool area trends of the two powders at different scanning speeds. Bottom: same trend for denudation width over melt-pool width. Laser power was set to $30 \mathrm{~W}$

The melt-pool area graph confirms the trend already shown by absorptance results: as the scanning speed increases, the meltpool becomes smaller, which is due to both lower energy input and higher reflectivity. The higher reflectivity for the iron oxide-doped powder is responsible for the different behaviors of the two powders above $40 \mathrm{~mm} / \mathrm{s}$. In fact, at high-speed, manganese oxide-doped alumina powder has a larger meltpool than the iron oxide-doped alumina powder.

At low scanning speed, the melt-pool size is similar, as expected, considering that the laser input and the absorptance are equal or similar.

The denudation zone is generally smaller for manganese oxide-doped powder, except for the case of scan speed equal to $12 \mathrm{~mm} / \mathrm{s}$, but, in this case, the difference between the two powders is not significant. In both cases, understanding the denudation mechanisms and quantifying the denudation zone may be important for process characterization, since denudation changes the properties of the powder bed in adjacent/following scan tracks.

\subsection{Absorptance measurements-full layers}

Figure 12 shows the box-plots of absorptance measured during the production of one entire layer consisting of nine scan tracks for all the parameter combinations in Table 2. When iron oxide-doped-powder is used, the first scan track has lower absorptance than subsequent ones, while when manganese oxide dopant is used, such effect is less evident. This result highlights the limitation of single track experiments for absorptance measurement, because depending on the material, a different behavior may be observed when multiple adjacent tracks are produced. The reason for the change in absorptance from the second scan onward is most likely the generation of new colored ternary crystalline phases, that was mentioned in Section 2.3 and analyzed in Makowska et al. [15] and Pfeiffer et al. [20]. Another possible explanation for the difference in absorptance between the first and the subsequent tracks was given by Zhang et al. [25]. They observed a difference in a photodiode signal when scanning the first track of the section, calling this phenomenon "edge effect." They attributed this phenomenon to the presence of the powder all around the melt pool, which reduces the heat dissipation heat and, thus, increases the melt-pool temperature. In the "fill vectors," the solidified tracks near the melt-pool cause higher conductivity, resulting in a lower melt-pool temperature.

This explanation, however, does not fit with the increase in absorptance from the second scan onward that was measured for the iron oxide-doped powder. In fact, a "cooler" melt pool should rather lead to lower absorptance. In addition, the thermo-dynamic explanation from the literature does not provide an explanation for the difference in behavior between the two dopants. The main effect plot in Fig. 13 also confirmed the higher mean absorptance obtained when iron oxide-doped powder is used compared to the manganese oxide-doped powder. The mean absorptance was also positively correlated with the energy density, which can be easily explained by the higher melt pool temperature and by keyhole effects. The slightly higher mean absorptance at $18.5 \mathrm{~W}$ compared to $10 \mathrm{~W}$ is more difficult to explain. Being equal the energy density, it could be assumed that the power should not have an impact on the meltpool size and temperature. However, an explanation could be that at high power, the scan speed is also higher, being the energy density fixed. At higher speed, 
Fig. 12 Box plot showing the absorptance for iron oxide-and manganese oxide-doped powders for different scan tracks during their first layer

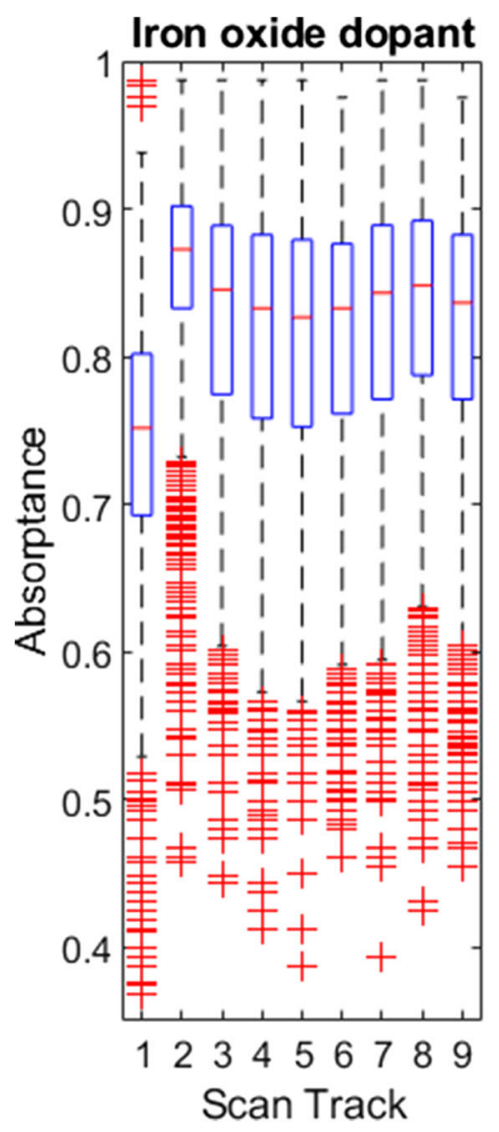

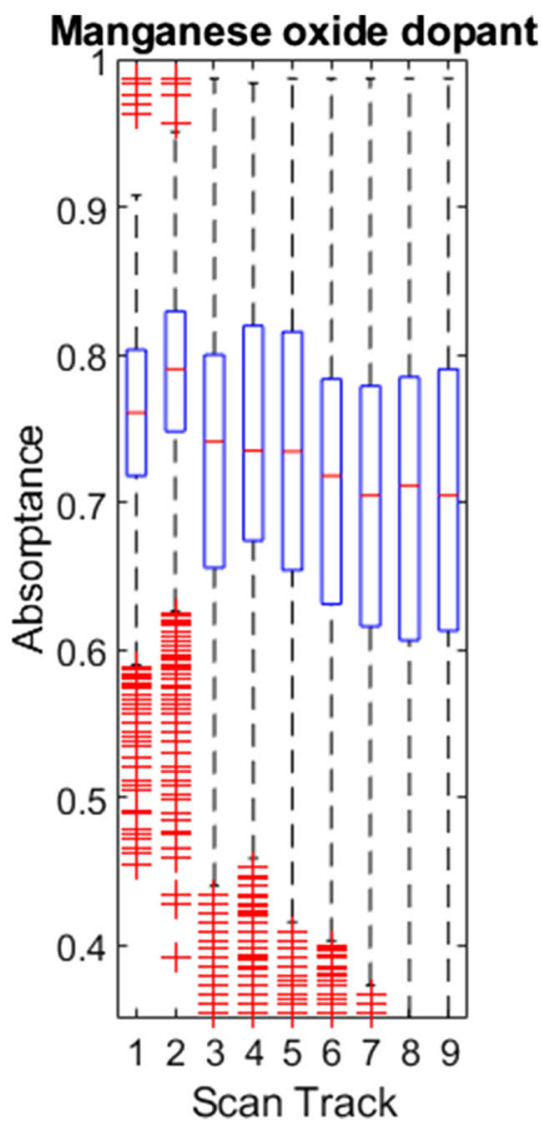

heat dissipation is less efficient, since there is less time for heat exchange to happen and therefore the melt-pool and surrounding temperature could be higher, which would then explain why the absorptance is also higher.
Fig. 13 Main effect plot for mean absorptance of full layers

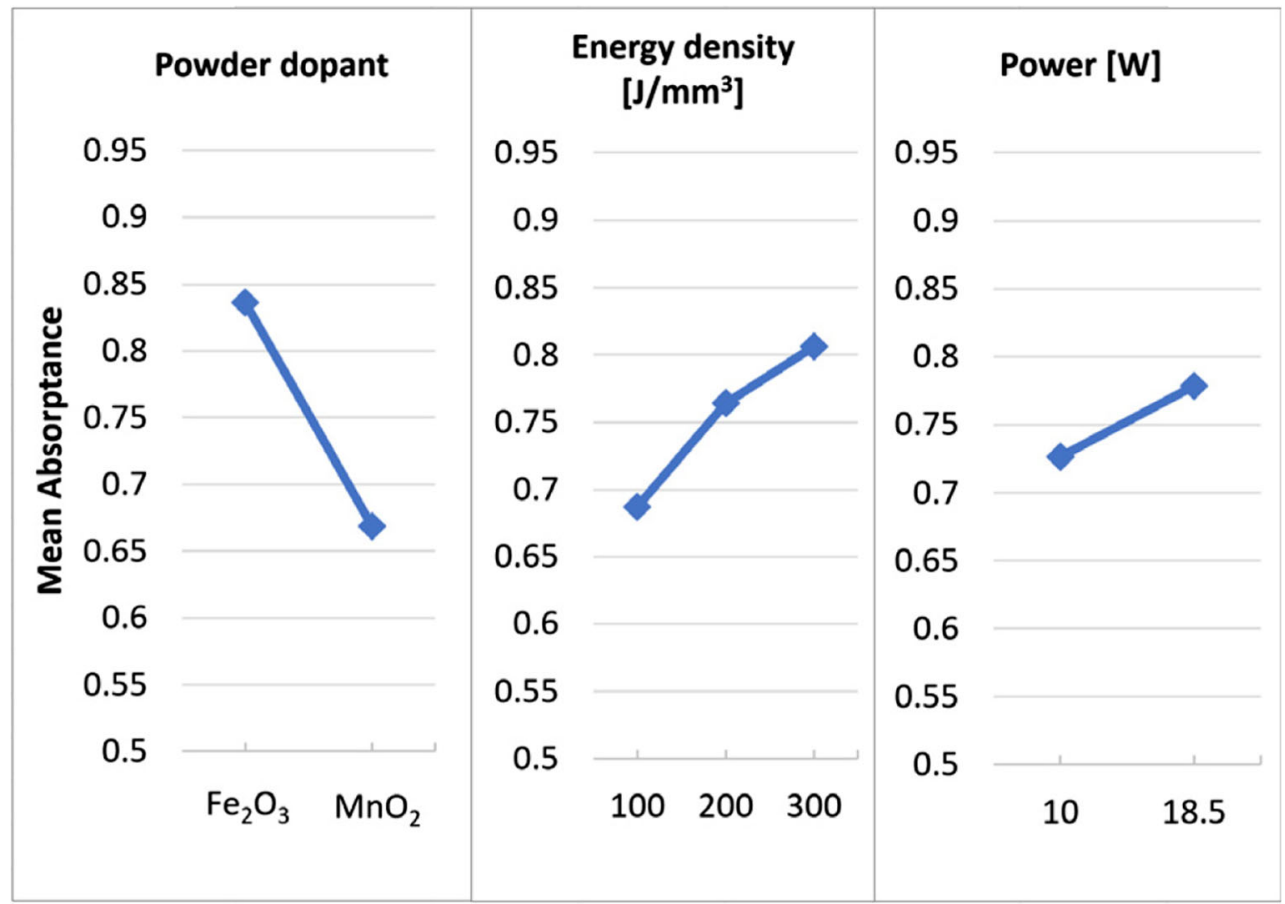



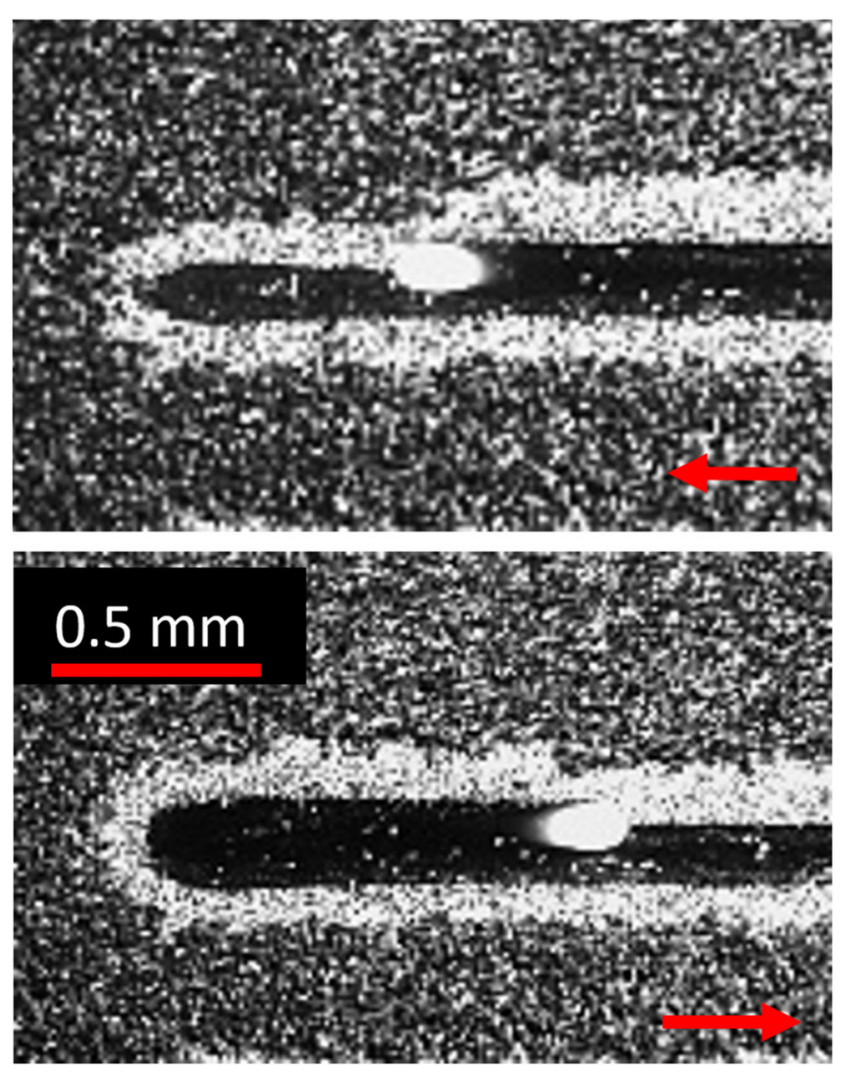

Fig. 14 Two high-speed camera pictures in two subsequent scan tracks. The red arrow indicates the direction of the laser scan. Laser power was $30 \mathrm{~W}$, scan speed was $40 \mathrm{~mm} / \mathrm{s}$.

\subsection{High-speed video image analysis—full layers}

Figure 14 shows two subsequent scan tracks built with laser power of $30 \mathrm{~W}, 170 \mu \mathrm{m}$ of spot size, and a speed of $40 \mathrm{~mm} / \mathrm{s}$. The hatch distance (distance between two laser scans) is set to
$125 \mu \mathrm{m}$. Considering the focus spot size, this would lead to an overlap of about $26 \%$ in the laser scan tracks. The melt-pool in the first scan is larger than the laser focus spot, as already observed for ceramics by Moniz et al. [9] and for metals by Heeling et al. [23]. Therefore, in the second scan track, roughly half of the laser power should irradiate the powder bed and the other half the previously molten scan track.

In reality, because of the denudation mechanism, almost no powder is present on the second and third track during subsequent laser scanning. However, as in previous tracks, the powder in the vicinity of the melt-pool is attracted by convection flows into the melt-pool. The result is that in subsequent laser scan tracks, less powder is incorporated by the melt-pool compared to the first scan track. This explains geometrical defects of final parts, such as taller contours experienced in the literature $[4,6]$, and highlights the need for observing the behavior of full layers, rather than single tracks.

Therefore, the same experiments proposed in Table 2 were performed for high-speed camera recordings as explained in Section 2.4.

The results of the layers are summarized in the main effect plot in Fig. 15. The results confirmed that the iron oxide dopant led to a more stable process compared to manganese oxide: in fact, the melt-pool area is in average about twice the one observed with the former powder. This difference could not be explained by the absorptance at room temperature, for which the manganese oxide powder should perform considerably better according to Pfeiffer et al. [20], nor by the single track results in Fig. 11, but it is clearly explained by the in-situ absorptance measurements shown in Fig. 13, where the iron oxide dopedpowder had considerably larger absorptance (84\%) than manganese oxide-doped powder $(66 \%)$.
Fig. 15 Main effect plot for mean melt pool area of full layers

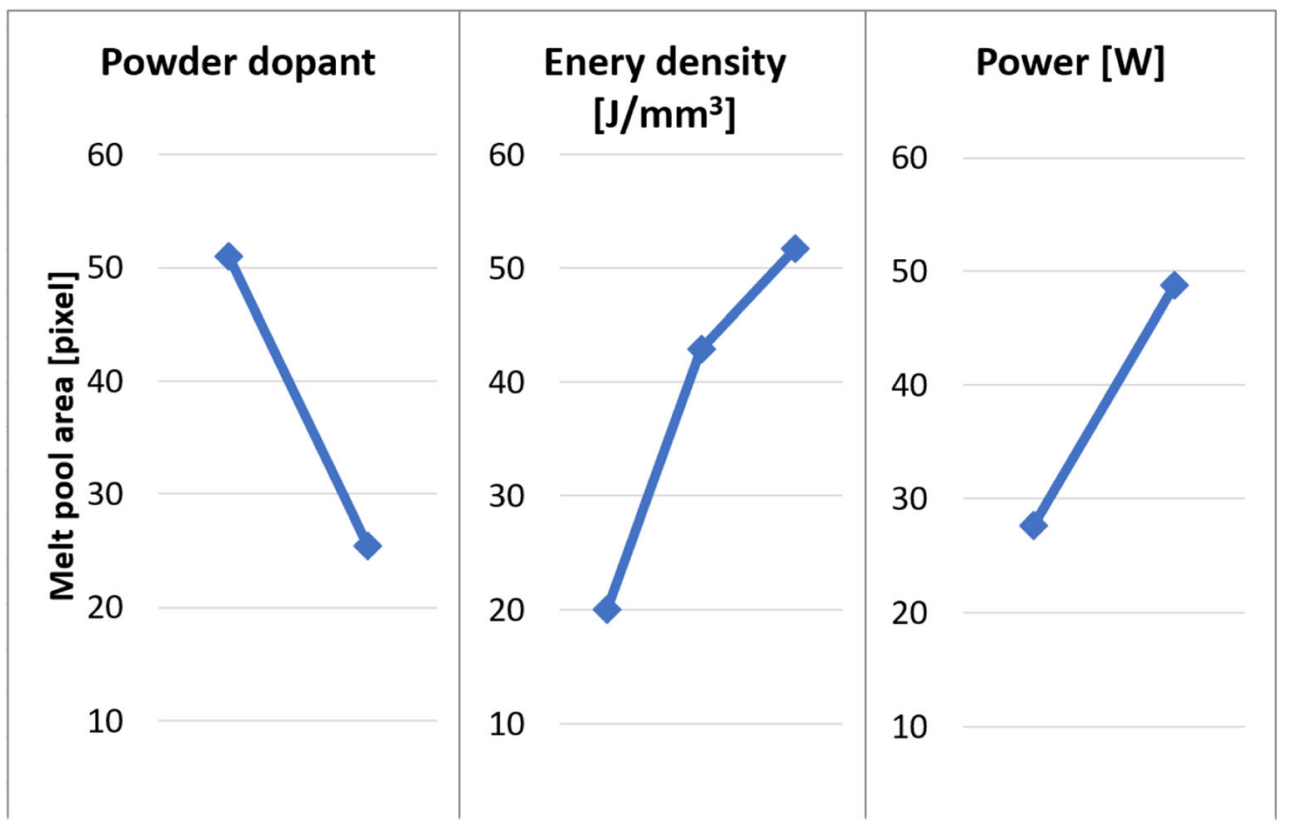


The results of the melt-pool size analysis are in agreement with the absorptance measurements.

The melt-pool size increases with the increasing of energy density and power. The difference between the two power levels, similarly to what revealed by absorptance analysis, is an indication that the energy density alone is not a reliable parameter to characterize the process, since the power and speed level have a large influence even if the energy density is kept constant.

\section{Conclusions}

Two process characterization techniques have been shown as useful tools for the choice of a suitable dopant for ceramics in L-PBF.

The absorptance measurement technique is a practical method to assess how much energy is absorbed by the system of substrate, powder, and melt-pool. It provides relevant information for L-PBF characterization and improvement.

The validity of absorptance measurements is confirmed by the comparison with melt-pool size and by the observations of melt-pool instability via in-situ high-speed video imaging.

High-speed video imaging also highlighted the effect of convection flows around the melt-pool. This generates a denudation zone, which will heavily influence the next laser scan track.

The influence of the crystalline structure in the subsequent tracks is also shown to be important. It was observed that a suitable doped powder must have high absorptance not only in its powder form, but also after laser melting and resolidification, since the absorptance of the previously scanned tracks and layers has an impact on the results, when full layers are scanned.

It was then concluded that the iron oxide-doped powder leads to larger and more stable melt-pool when the infrared 1070-nm laser is used, despite the lower absorptance of the iron oxide-doped in single tracks studies. These experiments also showed that it is not possible to find an easy and fast characterization method to predict, which is the best powder dopant, since at least a complete layer must be built. However, both in-situ absorptance measurements and high-speed camera recordings can be used to characterize the process and to monitor whether the process is stable and enough energy is absorbed by the system.

Future studies should focus on the development of better material systems, which could lead to more stable and dense parts. For instance, the amount of dopant and different dopants could be thoroughly investigated. However, the influence on the material properties has to be considered by these changes. Such developments are only possible through an appropriate characterization of the process, similar to what was presented here. The characterization setups could also be improved by implementing an in-line high-speed camera and an in-line external illumination, which could potentially enable to acquire both absorptance measurements and high-speed camera frames simultaneously.
Code availability Not applicable

Author contribution Florio K. drafted the article. Florio K., Puccio D., Viganò, G., Grasso M., and Pfeiffer S. collected and analyzed the data. Colosimo B.M. and Verga F. contributed to the interpretation of the data. Wegener K. and Graule T. conceived and designed the study and contributed to the interpretation of the data. All authors contributed with a critical revision of the article and gave the final approval of the published version.

Funding Open Access funding provided by ETH Zurich. This work was funded by ETH Institutions in the frame of the SFA (Strategic Focus Area) Advanced Manufacturing.

Data availability Raw absorption data and videos are available on request.

\section{Declarations}

Ethics approval and consent to participate Not applicable

Consent for publication Not applicable

Competing interests The authors declare no competing interests.

Open Access This article is licensed under a Creative Commons Attribution 4.0 International License, which permits use, sharing, adaptation, distribution and reproduction in any medium or format, as long as you give appropriate credit to the original author(s) and the source, provide a link to the Creative Commons licence, and indicate if changes were made. The images or other third party material in this article are included in the article's Creative Commons licence, unless indicated otherwise in a credit line to the material. If material is not included in the article's Creative Commons licence and your intended use is not permitted by statutory regulation or exceeds the permitted use, you will need to obtain permission directly from the copyright holder. To view a copy of this licence, visit http://creativecommons.org/licenses/by/4.0/.

\section{References}

1. Sing SL, Yeong WY, Wiria FE et al (2017) Direct selective laser sintering and melting of ceramics: a review. Rapid Prototyp J 23: 611-623. https://doi.org/10.1108/RPJ-11-2015-0178

2. Travitzky N, Bonet A, Dermeik B et al (2014) Additive manufacturing of ceramic-based materials. Adv Eng Mater 16: 729-754. https://doi.org/10.1002/adem.201400097

3. Zocca A, Colombo P, Gomes CM, Günster J (2015) Additive manufacturing of ceramics: issues, potentialities, and opportunities. J Am Ceram Soc 98:1983-2001. https://doi.org/10.1111/jace. 13700

4. Juste E, Petit F, Lardot V, Cambier F (2014) Shaping of ceramic parts by selective laser melting of powder bed. J Mater Res 29: 2086-2094. https://doi.org/10.1557/jmr.2014.127

5. Wilkes J, Hagedorn Y, Meiners W, Wissenbach K (2013) Additive manufacturing of $\mathrm{ZrO}_{2}-\mathrm{Al}_{2} \mathrm{O}_{3}$ ceramic components by selective laser melting. Rapid Prototyp J 19:51-57. https://doi.org/10.1108/ 13552541311292736

6. Verga F, Borlaf M, Conti L et al (2020) Laser-based powder bed fusion of alumina toughened zirconia. Addit Manuf 31:100959. https://oi.org/10.1016/j.addma.2019.100959 
7. Wilkes J, Hagedorn Y, Wissenbach K et al (2010) Net shaped high performance oxide ceramic parts by selective laser melting. Phys Procedia 5:587-594. https://doi.org/10.1016/j.phpro.2010.08.086

8. Gan MX, Wong CH (2018) Experimental studies on the properties of selectively laser melted alumina-spodumene composite. Ceram Int 44:19008-19015. https://doi.org/10.1016/j.ceramint.2018.07. 144

9. Moniz L, Colin C, Bartout J-D et al (2018) Laser beam melting of alumina: effect of absorber additions. Jom 70:328-335. https://doi. org/10.1007/s11837-017-2716-9

10. Fan Z, Lu M, Huang H (2018) Selective laser melting of alumina: a single track study. Ceram Int 44:9484-9493. https://doi.org/10. 1016/j.ceramint.2018.02.166

11. Liu J, Bai S (2017) Femtosecond laser additive manufacturing of YSZ. Appl Phys A Mater Sci Process 123:293. https://doi.org/10. 1007/s00339-017-0929-y

12. Zheng Y, Zhang K, Liu TT et al (2019) Cracks of alumina ceramics by selective laser melting. Ceram Int 45:175-184. https://doi.org/ 10.1016/j.ceramint.2018.09.149

13. Florio K, Pfeiffer S, Makowska M et al (2019) An innovative selective laser melting process for hematite-doped aluminum oxide. Adv Eng Mater 1801352:1-10. https://doi.org/10.1002/adem. 201801352

14. Pfeiffer S, Florio K, Makowska M et al (2019) Iron oxide doped spray dried aluminum oxide granules for selective laser sintering and melting of ceramic parts. Adv Eng Mater 1801351:1801351. https://doi.org/10.1002/adem.201801351

15. Makowska M, Pfeiffer S, Casati N et al (2019) Pre-processing of hematite-doped alumina granules for selective laser melting. Ceram Int 45:17014-17022. https://doi.org/10.1016/j.ceramint.2019.05. 251

16. Qian B, Taimisto L, Lehti A et al (2014) Monitoring of temperature profiles and surface morphologies during laser sintering of alumina ceramics. J Asian Ceram Soc 2:123-131. https://doi.org/10.1016/j. jascer.2014.01.009

17. Wilkes JI (2009) Selektives Laserschmelzen zur generativen Herstellung von Bauteilen aus hochfester Oxidkeramik. Rheinisch-Westfälischen Technischen Hochschule Aachen
18. Hagedorn Y (2013) Additive manufacturing of high performance oxide ceramics via selective laser melting. Rheinisch-Westfälischen Technischen Hochschule Aachen

19. Moniz L, Colin C, Berger M-H, Bartout J-D (2017) Laser-matter interaction model of laser beam melting applied to oxide ceramics and comparison with metallic alloy. International Congress on Applications of Lasers \& Electro-Optics 2017:509. https://doi.org/ 10.2351/1.5138151

20. Pfeiffer S, Florio K, Makowska M et al (2020) Selective laser melting of thermal pre-treated metal oxide doped aluminum oxide granules. Open Ceramics 2:100007. https://doi.org/10.1016/j.oceram. 2020.100007

21. Bityukov VK, Petrov VA (2013) Absorption coefficient of molten aluminum oxide in semitransparent spectral range. Appl Phys Res 5:51-71. https://doi.org/10.5539/apr.v5n1p51

22. Petrov VA (2009) Abrupt increase of the absorption coefficient of alumina at melting by laser radiation and its decrease at solidification. Int J Thermophys 30:1938-1959. https://doi.org/10.1007/ s10765-009-0678-z

23. Heeling T, Cloots M, Wegener K (2017) Melt pool simulation for the evaluation of process parameters in selective laser melting. Addit Manuf 14:116-125. https://doi.org/10.1016/j.addma.2017. 02.003

24. Matthews MJ, Guss G, Khairallah SA et al (2017) Denudation of metal powder layers in laser powder-bed fusion processes. Addit Manuf Handb Prod Dev Def Ind 114:677-693. https://doi.org/10. 1201/9781315119106

25. Zhang K, Liu T, Liao W et al (2018) Photodiode data collection and processing of molten pool of alumina parts produced through selective laser melting. Optik 156:487-497. https://doi.org/10.1016/j. ijleo.2017.11.143

Publisher's note Springer Nature remains neutral with regard to jurisdictional claims in published maps and institutional affiliations. 